\title{
A Study on Implementation of Lean Techniques in High Raised Structure in Mangalore
}

\author{
Deekshith B Shetty \\ PG Student, Dept of Civil Engineering \\ NMAMIT ,Nitte. \\ Udupi District, Karnataka-574110
}

\author{
Mr. Sundip Shenoy R \\ Assistant Professor \\ NMAMIT,Nitte. \\ Udupi District,Karnataka-574110
}

\begin{abstract}
In the construction sector, preserving a balance between concert, quality and price, while satisfying customers, has become a contest for building materials producers, designers and contractors. This challenge led to the documentation and use of new materials and construction systems. Construction engineering projects are closely related to commercial issues; therefore, improving the sustainability of the materials used in these developments can contribute to achieving sustainable development in general. This research work is proposed with the hope that the use of this method can give similar results for those of the selected site. What in turn will help to minimize waste, will provide efficiency in work and will also increase quality of the construction of the selected project.
\end{abstract}

Keywords - Lean, Look Ahead Plan, Last Planner System, PokaYoke.

\subsection{INTRODUCTION}

India is one of the fastest emerging country in the world. Nowadays India has shown a great progress in almost all the fields.Construction is one of the most important factor that pays to the development of any nation. Construction in all countries is being practised from ages.Construction has always proved that it cannot attain the expected quality. Cost overrun is also one of the main problem that is being faced by the clients as well as the contractors. No matter how much effort the contractor puts in reducing the waste in construction site till date it has not shown any fruitful result. Because of the wastes there will be a scarcity of materials and most of the contractors will make compromise in the quality of the work. The project getting delayed has become one of the most common problem in almost all the construction companies.These type of problems can be eliminated by implementation of lean principles.By implementing the lean concept and the lean principles the project can be completed within the given time. It also helps in improving the quality of the work. So study of Lean tool implementation has become one of the most important criteria in construction nowadays. It helps in eliminating the non-value added activities in construction work which causes loss of quality and profit in other terms.In our project we have used two most effective lean tools known as Last Planner System and Poka-Yoke.The lean tools was implemented on a high raised structure in Mangalore.

\subsection{OBJECTIVES OF THE WORK}

1. To minimize the unwanted material waste, provide proper efficiency in the work and provide proper quality in the construction activities.

\section{Implementation of Lean Principles and comparison among the other methods.}

\subsection{LITERATURE REVIEW}

Ossama M. Salem,et.al;(2005)[1] :The goal of this paper is to test the effectiveness of some lean construction tools, in particular, those tools that can be applied in medium size construction firms. Due to the success of the lean production system in manufacturing, the construction industry has adapted lean techniques to eliminate waste and increase profit. A field study was conducted to evaluate the effectiveness of some lean construction techniques including last planner, increased visualization, daily huddle meetings, first run studies, the $5 \mathrm{~s}$ process, and fail safe for quality. The data collection methods included direct observations, interviews, questionnaires, and documentary analysis. The effectiveness of the lean construction tools was evaluated through the lean implementation measurement standard and performance criteria. It was found that last planner, increased visualization, daily huddle meetings, and first run studies achieved more effective outcomes than expected. However, the results of implementation of 5 s process and fail safe for quality did not meet the expectations of the tool champions and the research team. It was found that there is need for behavioral changes and training for effective use of lean tools. Most of the lean construction tools selected for the project are either ready to use, or are recommended with some modifications. A summary of the results is provided, and future research needs are outlined. The project was completed on time and within the agreed budget. Indeed the saving of $£ 33$ per $\mathrm{m} 2$ (ie $£ 734$ - $£ 701$ per $\mathrm{m} 2$ ) equated to a further saving of $£ 1.65 \mathrm{~m}$ on the agreed construction budget Construction costs on a like for like inflation adjusted basis were $40 \%$ lower than on a similar plant built on the same site some eleven years earlier.

O. Salem, M.ASCE;et.al;2006[2] This article compares the techniques developed for lean construction with those developed for lean manufacturing. Lean manufacturing and lean construction techniques share many common elements despite the obvious differences in their assembly environments and processes. Manufacturing plants and construction sites are different in many ways that might explain why lean production theories and practices do not fully fit the construction industry. Though many lean construction tools and elements are still in an embryonic state, lean construction techniques are gaining popularity because they can affect the bottom line of projects. Additionally, this paper presents a study of a construction project in which 
specific lean construction elements were tested. Each technique was evaluated in terms of its impact on the performance of the project. Based on the findings of the study, a new "lean assessment tool" is proposed to quantify the results of lean implementations. The assessment tool evaluates six lean construction elements: last planner, increased visualization, huddle meetings, first-run studies, five S's, and fail safe for quality. This paper provides a simple and comprehensive approach that is transferable to any construction project.The benefits of the implementation were tangible: the project was under budget and three weeks ahead of schedule, and subcontractors were more satisfied with their relationships with the GC. The average PPC value was $76 \%$, 20 points above the initial performance. No major injuries occurred during the project, and the incident rate was below that for similar projects in the same company. Most of the planners associated the performance of the project with the implementation of the lean construction techniques, and they would like to continue with most of the tools. In particular, they enjoyed the learning process involved in the new approach of lean construction.

Ramin Sadri, Pouya Taheri,et.al; (2011)[3] ;This study shows that the estimated costs of rework in construction is almost equal to $4-5 \%$ of the contract value. The study also highlights how Poka-Yoke implementation in construction site helps us to eliminate the waste caused by errors. A case study was also conducted on an actual building project in which a trolley hoist was used to haul bricks between the ground level and various floors. The case study proved that by a small investment a simple Poka-Yoke technique can bring about a drastic change in productivity. It also helped in reducing the project time and a cost in a period of few days

Gao Shang,et.al; (2014)[4] ;By this study we can say that the Last Planner System is known as a production planning system designed to produce predictable and reliable workflow, but has not been much discussed in the context of the Chinese construction industry. This paper is arguably one of the pioneering studies to investigate the implications of LPS for the planning system employed in Chinese construction firms. By reviewing the current project planning practices at Chinese construction projects, this study uncovers several areas of common ground between LPS and the Chinese way of project planning. Structurally, both contain similar hierarchical components for the different levels of details for plan needs. However, several crucial elements of LPS, the look-ahead plans and PPC in particular, were not commonly seen in China. Apart from the technical aspects, the most significant difference appears to lie in the soft factors: for example, Chinese PMs do not empower foremen to take ownership of project planning with commitments built in. Having identified these differences, the SWOT analysis was carried out to investigate potential factors that might impact LPS implementation in China.

Ase I. Nestebya,et.al; 2016[5] The presence of the challenges relating to BREEAM-NOR in projects identified in the preliminary literature study were confirmed in the case study. Furthermore, the overall findings from the same study are also consistent with the performed research. Statements from conducted interviews in the BREEAM-NOR projects support the theory that they are governed by a push-strategy from management. They also showed that BREEAM-NOR and LPS run as two parallel components in the project. Based on the research in this article, the conclusion is drawn that BREEAM-NOR should without further complications be possible to integrate into the LPS-system of a project. This will help turn the push strategy towards pull-strategy. A prerequisite is that the LPS-structure applied in the project is optimized, which is not the current situation in the studied projects. Even though today's situation does not portray an optimal implementation of LPS, it has been confirmed through interviews that LPS has had a positive effect on the projects. It was deemed a useful planning tool and had increased involvement of all squad bosses. This substantiates the preliminary study's conclusion and strengthens the notion that the positive pull-effects of LPS can reduce the pushrelated challenges of BREEAM-NOR projects.

Piotr Nowotarskia,, Jerzy Pasawskia,et.al;2016[6] The study shows that Construction sector is in general characterized by frequent deadlines delays, budget overruns and problems in maintaining proper quality. To prevent such problems, a common practice is to transfer the management methods used successfully in production industry. The paper presents the idea of introducing Lean Management methodologies in chosen construction processes and the purpose of the study is to show how Lean Management can influence the total cost of selected process of managing storage area on the construction site. Article is based on the study conducted by authors on the construction of office building in Poznan (Poland) city center, where proposed new approach to management was introduced and tested. Authors performed deeper analysis on introducing proposed methodology into 3 processes: column concreting, storage area management and scaffolding ordering. In the article authors focused their attention on economic aspects of introduced changes into one of them: storage area management, showing how proposed different style of management can influence costs of analyzed processes. Lean methodologies are used to assess the risk problems and find suitable solution which will influence on reduction of the total time and cost of analyzed works.

Oluwatosin Babalola,et.al (2018)[7]:The study shows how the implementation of lean principles and approaches is gaining grounds in the construction industry globally. However, there is no clear understanding of the number and categories of lean practices implemented and the benefits associated with it in the planning, design and construction of building and infrastructure projects. Totally, 103 documents published between 1996 and 2018 were reviewed and their contents analysed using descriptive statistics and content analysis. A total of 32 different lean practices categorised into design and engineering; planning and control; construction and site management; and health and safety management were identified. The review also found that the last planner system and just-in-time were the top two most implemented lean practices and about 20 different economic, social and environmental benefits were linked to the implementation of lean practices in the construction industry.

M.Dhivakar,Karthick,et.al (2018)[8]:The research involved the identification of the key wastes along with their sources using a questionnaire based survey. As obtained from the analysis of questionnaires collected, Delays and Rework were 
the most critical wastes plaguing the construction practices. Their sources as found by Poor Management Control, Poor Planning and Shortage of the Resources Used. Phase 2 of the project involved the implantation of the Last Planner System at the extension to reduce / remove the wastes identified from the survey. It was observed that much more improvement could have been achieved if the contractor would have taken keen interest in the implementation of the LPS. There was also lack of interest among all the authorities to sit for a weekly review meeting to solve the problems causing the plan failures. The following recommendations are made on the basis of this research to improve the construction scenario.

- Weekly review meetings at all sites (1 site per day) in which all parties sit down and review the work done in the previous week, solve the problems to prevent reoccurrence, make look ahead plans and weekly plans using the LPS.

- As the Engineering cell is understaffed at the moment, it is recommended that a dedicated project management team be formed which will maintain the weekly plans to keep track of the project and organize the review meetings.

Daniel Heigermosera,et.al; 2019[9] The study shows that the productivity of the AEC industry has experienced a slow growth for several decades. In the last 50 years, productivity has dropped by almost $20 \%$. Some reasons include an insufficient knowledge transfer from project to project, the lack of realistic site information, and a weak short-term planning and work plans. The development of BIM and other technologies, such as augmented reality, drones, and advanced building materials, which have all reached market maturity, has vast potential for improving productivity and efficiency in the AEC industry. To utilize the enormous potential a committed and collaborative effort will be required by the whole industry This study shows that, when combining Lean Construction practices with BIM, a collaborative environment that genuinely minimizes both tangible and intangible wastes in a construction project can be created.

Subhav Singh, Kaushal Kumar 2019[10] This study provides us with a review of the systematic literature review of the lean tool and lean construction papers published in the time frame from 2008 to 2018. The papers selected from the Scopus database by using the following filters: ten top-rated journals selected on the basis of cite score form Scopus, the only article having a key words "lean construction", or "Lean tool" were selected.The paper shows the most effective tool of the lean management. The last planner system, Poka-Yoke, $5 \mathrm{~S}$ and JIT are seen to be the most effective tool of lean management.

\subsection{METHODOLOGY}

Methodology is an identical way to find out the product of the research problem. It is a science of studying how a research is to be conducted and illustrates the work plan of the research.

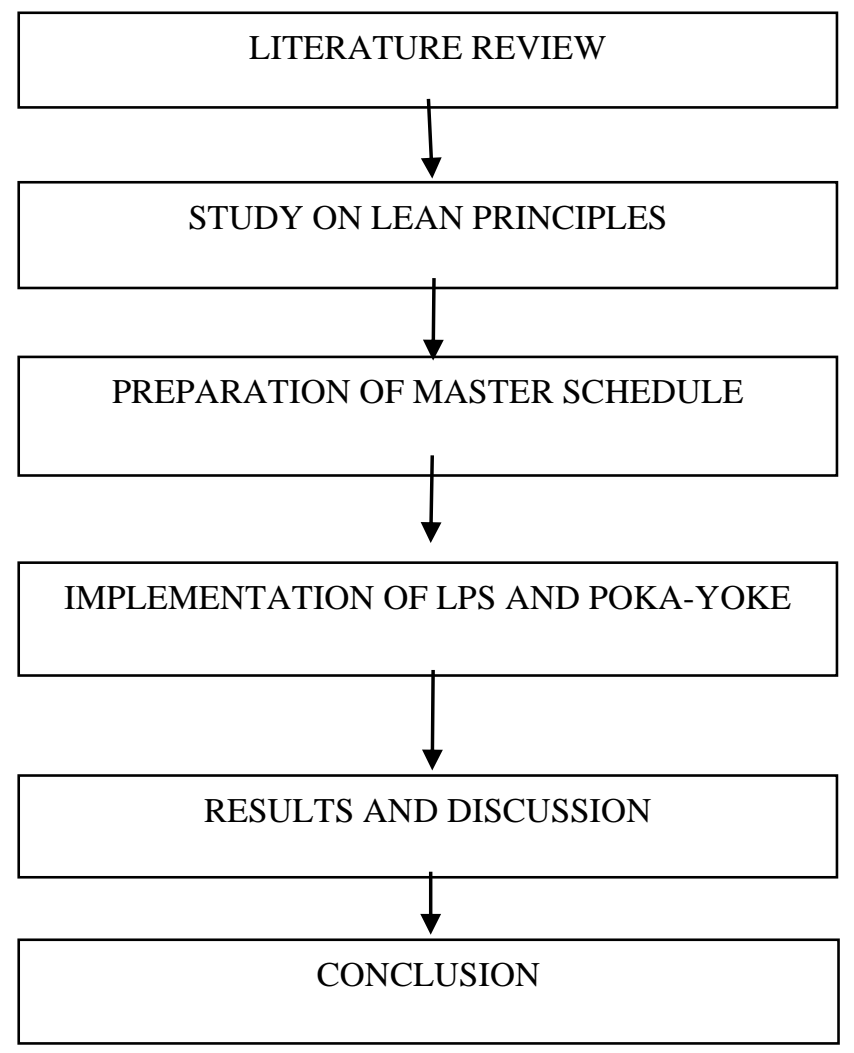

\subsection{IMPLEMENTATION OF LAST PLANNER SYSTEM}

This lean tool can be implemented in the construction of high raised structure High Crest at Mangalore my keen was completing the work within the duration and decreasing the cost of construction and saving the time and resources. By analyzing all the delays in the site, we found that this lean tool can be useful to overcome the delay in the project.

The Last Planner system is a lean tool, aims at increasing the faith in planning. Increasing plan reliability is done by taking action at several levels in the planning system.

The Last Planner planning cycle mainly consists of the master schedule covering an entire project, the look-ahead plan with problem analysis and the weekly work plan to measure percent plan complete.

The Master schedule: it mainly consists of sequence of activities and identifies all the works and the obstacles in the activity that has to be removed. It mainly defines what has to be done.

Look ahead Plan: in brief it mainly consists of planning for four or six weeks as per the master schedule, and it contains the details of the activities which has to be reached as per the schedule.

Weekly Work Plan (WWP): it can be termed as short term planning, it consists of sequence and size of the work that has to be completed in that week.

Percent Plan Complete $(\mathrm{PPC} \%)=$ Number of tasks completed /Total number of Activities $\times 100$ 


\begin{tabular}{|l|c|c|c|c|}
\hline Weeks & $\begin{array}{c}\text { Total no of } \\
\text { Activities }\end{array}$ & $\begin{array}{c}\text { No. of } \\
\text { Tasks } \\
\text { Completed }\end{array}$ & $\begin{array}{c}\text { No. of } \\
\text { Incomplete } \\
\text { tasks }\end{array}$ & $\begin{array}{l}\text { PPC } \\
(\%)\end{array}$ \\
\hline $\begin{array}{l}01 / 01 / 20- \\
07 / 01 / 20\end{array}$ & 10 & 7 & 3 & 70.0 \\
\hline $\begin{array}{l}08 / 01 / 20- \\
14 / 01 / 20\end{array}$ & 7 & 6 & 1 & 85.7 \\
\hline $\begin{array}{l}15 / 01 / 20- \\
21 / 01 / 20\end{array}$ & 6 & 6 & 0 & 100.0 \\
\hline $\begin{array}{l}22 / 01 / 20- \\
28 / 01 / 20\end{array}$ & 6 & 4 & 2 & 66.6 \\
\hline $\begin{array}{l}29 / 01 / 20- \\
04 / 02 / 20\end{array}$ & 4 & 2 & 2 & 50.0 \\
\hline & 33 & 25 & 8 & 75.7 \\
\hline
\end{tabular}

Table 4.1.1: Look Ahead Plan 1

From daily analysis and collection of data PPC from look ahead plan 1 was calculated. The average PPC is seen to be $75.7 \%$.

\begin{tabular}{|l|c|c|c|c|}
\hline \multicolumn{1}{|c|}{ Weeks } & $\begin{array}{c}\text { Total no of } \\
\text { Activities }\end{array}$ & $\begin{array}{c}\text { No of } \\
\text { Tasks } \\
\text { Completed }\end{array}$ & $\begin{array}{c}\text { No of } \\
\text { Incomplete } \\
\text { tasks }\end{array}$ & $\begin{array}{c}\text { PPC } \\
(\%)\end{array}$ \\
\hline $\begin{array}{l}05 / 02 / 20- \\
11 / 02 / 20\end{array}$ & 11 & 9 & 2 & 81.82 \\
\hline $\begin{array}{l}12 / 02 / 20- \\
18 / 02 / 20\end{array}$ & 10 & 8 & 2 & 80.0 \\
\hline $\begin{array}{l}19 / 02 / 20- \\
25 / 02 / 20\end{array}$ & 4 & 4 & 0 & 100.0 \\
\hline $\begin{array}{l}26 / 02 / 20- \\
03 / 03 / 20\end{array}$ & 4 & 4 & 0 & 100.0 \\
\hline $04 / 03 / 20-$ & 7 & 6 & 1 & 85.70 \\
$10 / 03 / 20$ & 36 & 31 & 5 & 86.11 \\
\hline & & &
\end{tabular}

Table 4.1.2: Look Ahead Plan 2

The Look Ahead Plan 2 for the second month was implemented and the PPC was recorded by collecting the data. The average PPC for Look Ahead Plan 2 was found to be $86.1 \%$ which is higher than that of the first month.

\subsection{IMPLEMENTATION OF POKA-YOKE}

In Poka Yoke we first need to identify and list down all the problems that may occur in the construction site. These problems are listed down based on the past experience of the site engineer or the contractor. Problems are also identified during the weekly meeting between the client, engineer and the contractor. In my project the problems that may occur in the site are listed down for a period of 1 month.

After listing down of the problems the source from which the problem occurs has to be found out. This is mainly executed by the site engineer or the site in charge who is present at the site. Detection of the source helps in reduction of the continuous occurrence of the same problem. However, in practical in construction site even though the source of problem is known, sometimes the problems will occur at most often rate. It is mainly because of the misunderstanding or miscommunication between the labours, site engineer or any other person who is related to the construction site.

Conducting a weekly meeting at the construction site plays an very important role in implementation of Poka-Yoke. After identification and detecting the problems the solution for these has to be derived. The solution to these problems is derived in the weekly meeting which consists of client, contractors, engineers and other staffs who work on the site. In this project after the meeting with client contractors and engineers the problems were divided into two types;

They are;

1. Material Related Problems

2. Non material or labour related problems.

All the problems that may occur in the month of March-April 2020 were listed down and the solution for the same was derived.

In a weekly meeting all other problems which was not in the list will be recorded by the site engineer and these problems will be highlighted in front of other officials during the weekly meeting. Solution to these problems will be derived during this meeting.

After a certain period of time the most occurred problems are highlighted in terms of Red, Orange and Green colour indicators.

Red being the most occurred problem; which requires more attention.

Orange is moderate; which also requires a attention Green is very rare and not occurred.

\begin{tabular}{|c|c|}
\hline Material Related Problems & Solution to the Problem \\
\hline Machineries Breakdown & $\begin{array}{c}\text { Having an extra machinery or } \\
\text { an mechanic whose available at } \\
\text { site. }\end{array}$ \\
\hline Improper placing of materials & $\begin{array}{c}\text { Material has to be placed on a } \\
\text { proper and suitable platforms }\end{array}$ \\
\hline Mishandling of materials & $\begin{array}{c}\text { Wastage has to be minimized. } \\
\text { Proper record of the materials } \\
\text { has to be maintained. }\end{array}$ \\
\hline Shortage of the materials & $\begin{array}{c}\text { Required amount of the } \\
\text { materials has to be stored or has } \\
\text { to inform early so that the } \\
\text { material can reach the site on } \\
\text { time. }\end{array}$ \\
\hline
\end{tabular}

Table 4.2.1: List of Material Related Problems

\begin{tabular}{|c|c|}
\hline Non-Material Related Problems & Solution to the Problems \\
\hline Stagnant Water & Prevention of water blockage. \\
\hline Labour Problems & $\begin{array}{c}\text { Having a good relationship with } \\
\text { labours }\end{array}$ \\
\hline Defective work & $\begin{array}{c}\text { Proper method of working has to } \\
\text { be followed }\end{array}$ \\
\hline Miscommunication & $\begin{array}{c}\text { Proper and clear message has to be } \\
\text { given. }\end{array}$ \\
\hline Health Issues & $\begin{array}{c}\text { First aid kits should be readily } \\
\text { available at site. }\end{array}$ \\
\hline Transportation & $\begin{array}{c}\text { Proper transportation facilities } \\
\text { have to be provided }\end{array}$ \\
\hline
\end{tabular}

Table 4.2.2: List of Non-Material Related Problems

\subsection{RESULTS AND DISCUSSION}

The two main effective lean tools were implemented on the high raised structure in Mangalore. The two main effective 
lean tools known as Last Planner System and Poka-Yoke was implemented on a $\mathrm{G}+14$ storey residential building.

The master plan or a schedule for a $\mathrm{G}+14$ storey building was prepared using a software called PRIMAVERA. The master schedule was planned only for the structural part of the building.

The LPS was then implemented from the month of January to March ie for a period of almost 2 months. These 2 months are divided into two phases such as Look Ahead Plan 1 and Look Ahead Plan 2.

During the Look Ahead Plan 1 the weekly work plan was prepared. The activities that needs to be done in a particular week was properly planned in advance and an attempt was made to complete those tasks on time. This process is maintained and monitored up to 4 to 6 weeks or a month. At the end of the month or at the end of the Look Ahead Plan 1 the percentage plan complete was calculated. The same procedure was followed for Look Ahead Plan 2 or for the month of February to March 2020.

The percentage plan complete of Look Ahead Plan 1 and Look Ahead Plan 2 was compared and it was found that the PPC during first phase was $75.7 \%$ whereas at the end of the second phase the PPC was found to be $86.1 \%$. This result clearly showed us that the LPS not only helps us in reducing the construction time but it also helps us in maintaining a arranged and a proper planned work flow.

After the implementation of LPS for 2 months the second lean tool Poka-Yoke was implemented. Poka-Yoke is one of the most theoretical lean tool because in Poka-Yoke we cannot calculate PPC as we calculated in LPS.

The list of problems and the solution to those problems for the month of March-April 2020 was listed down. The work was carried out as per the plan.

After a certain period of time or after listing of all the problems, it can be divided into 3 zones. Red, Orange and Green indicators can be used.

Red being the most occurred problem in the site and requires more attention, Orange being the moderate requires less attention then that of Red Zone and green being the most rare or does not occur.

In our project we can say that LPS was more effective than Poka- Yoke. Because in LPS we can have a proper work flow, plan and properly arranged activities as well as we can maintain the schedule by calculating PPC.

Poka-Yoke being completely theoretical it requires a lot more time to be more effective at the site. But once it is properly arranged we can say it can be a great lean tool which can provide us a smooth and conflict free work environment.

\subsection{CONCLUSION}

- The master schedule of the project was developed which includes the total number of activities more than 85.

- By implementing LPS we can reduce the duration of the project by two to three months.

- By applying LPS we were also able to form an arranged work flow.

- It also helps in the reduction of conflicts between the employs.
- LPS was also seen to be the more effective lean tool than that of Poka-Yoke.

- Poka-Yoke can be much effective for smal construction sites.

- LPS is more detailed and has a proper schedule than that of Poka-Yoke.

\subsection{REFERENCES}

[1] Ossama M. Salem, J. Solomon, A. Genaidy, and M. Luegring.” Site Implementation and Assessment of Lean Construction Techniques", Lean Construction Journal (LCJ) · January 2005.

[2] O. Salem, M.ASCE, J. Solomon, A. Genaidy and I. Minkarah. "Lean Construction: From Theory to Implementation",10.1061/ ASCE 0742-597X 2006 22:4 168.

[3] Ramin Sadri, Pouya Taheri, Pejman Azarsa and Hedayat Ghavam "Improving Productivity through Mistake-Proofing of Construction Processes", International Conference on Intelligent Building and Management 2011.

[4] Gao Shang a,,Low Sui Pheng,” The Last Planner System in China's construction industry - ASWOT analysis on implementation", School of Architecture and the Built Environment, The University of Newcastle (Singapore Campus), 248373, Singapore b Department of Building, National University of Singapore, 117566, Singapore

[5] Åse I. Nestebya, Marie E. Aarrestada, Jardar Lohnea, Rolf A Bohnea." Integration of BREEAM-NOR in construction projects: Utilizing the Last Planner System", SBE16 Tallinn and Helsink Conference; Build Green and Renovate Deep, 5-7 October 2016, Tallinn and Helsinki.

[6] Piotr Nowotarskia,*, Jerzy Pasawskia, Jakub Matyjaa" Improving Construction Processes Using Lean Management Methodologies Cost Case Study", a Institute of Structural Engineering, Pozna University of Technology, Piotrowo 5, 60-965 Pozna, Poland.

[7] Oluwatosin Babalola, Eziyi O. Ibem, Isidore C. Ezema." Implementation of lean practices in the construction industry: A systematic review", Department of Architecture, Covenant University, Ota, Ogun State, Nigeria.

[8] M. Dhivakar KarthickS. Vimal Kumar, J. Sujith, K. Praveenth" Application of Lean Construction to Improve Material Management in Construction Project", International Journal of Engineering Research \& Technology (IJERT) ISSN: 2278-0181.

[9] Daniel Heigermosera,, Borja García de Sotob,c,, Ernest Leslie Sidney Abbottd, David Kim Huat Chuad.” BIM-based Last Planner System tool for improving construction project management", Published by Elsevier Ltd, www.elsevier.com/locate/autcon

[10] Subhav Singh, Kaushal Kumar." Review of literature of lean construction and lean tools using systematic literature review technique (2008-2018), Department of Civil Engineering, K.R. Mangalam University, Gurgaon, India Department of Mechanical Engineering, K.R. Mangalam University, Gurgaon, India. 